\title{
Determination of the Tetramer-Dimer Equilibrium Constant of Rabbit Hemoglobin
}

\author{
Babalola, J. O. \\ Chemistry Department, Faculty of Science, University of Ibadan, Nigeria,
}

Oyelakin, O. O.

Department of Science and Technology, University of The Gambia, Serrekunda, The Gambia.

Professor Okonjo, K. O.

Chemistry Department, Faculty of Science, University of Ibadan, Nigeria,

Brown-Acquaye, $\mathbf{K}$

University of Education, Winneba, Ghana

\begin{abstract}
Hemoglobin is a tetrameric protein which is able to dissociate into dimers. The dimers can in turn dissociate into tetramers. It has been found that dimers are more reactive than tetramers. The difference in the reactivity of these two species has been used to determine the tetramerdimer dissociation constant of various derivatives of rabbit hemoglobin. The constant has been found to be the same for all the derivatives of rabbit hemoglobin, implying that the ligand bound on the heme has no significant effect on the tetramer-dimer dissociation of rabbit hemoglobin.
\end{abstract}

\section{Introduction}

Proteins are capable of undergoing aggregation-disaggregation and association-dissociation. The former occurs in the form of protein-protein interactions involving high molecular weight proteins. In the case of the latter, a high molecular weight, multiple subunit molecule is broken down into intact smaller molecular units usually capable of carrying out the normal physiological functions of the parent molecule. Aggregation-disaggregation phenomenon in proteins has some physiological and pathological effects.

An example is the aggregation of hemoglobin S molecules to form long fibres. This results in sickle cell anemia. Thrombocytes are able to aggregate together such that this results in sickness and eventually death ${ }^{1}$. Alzheimer's disease is characterized by the formation of beta-amyloid bond which can be dissolved by denaturing agents ${ }^{2}$. The formation of the bond is an aggregation process. In cases of chronic renal failure, oxidized glutathione may react with hemoglobin, leading to protein aggregation in erythrocytes, which in turn leads to hemolysis. This is important in the pathogenesis of anemia in hemodialyzed patients ${ }^{4}$.

Several factors are known to influence association-dissociation, namely, protein concentration, ionic strength, $\mathrm{pH}$, temperature, allosteric effectors, electrolytes, ligands and denaturing agents $5,6,7,8$. The effect of each factor is determined by the nature of the protein.

Hemoglobin consists of two alpha and two beta polypeptide chains. The molecule is capable of dissociating into two alpha-beta dimers. The dissociation can go further to the stage of monomers. However, this last step can be prevented by the addition of the sodium salt of ethylenediaminetetraacetic acid $\left(\mathrm{Na}_{2} \mathrm{EDTA}\right)$. The dissociation of hemoglobin is a reversible process and the individual subunits maintain their oxygen binding capacity.

Certain conditions tend to enhance the dissociation of tetrameric hemoglobin. Some of these are: neutral $\mathrm{pH}$, moderate ionic strength, (0.1) and low protein concentration. At low concentrations of hemoglobin, the dimer form of hemoglobin is abundant in solution. Concentrated salt solutions promote dissociation of ligand bound hemoglobin into subunits. There is an observed increase in dissociation with increasing ionic strength.

The hemoglobins of all vertebrate animals are identical in their tetrameric and dimeric nature. The phenomenon of association-dissociation is therefore general to all the hemoglobins. The effect of strong 
salts is similar in all cases, be it mammals (that is, man, horse, sheep, rabbit etc.); birds (chicken, duck, pigeon); reptiles, fish and amphibians ${ }^{8}$. Rabbit hemoglobin is used for this work.

Different methods have been used to measure the tetramer-dimer equilibrium constant of hemoglobin. Some of these include: flash photolysis ${ }^{6,14}$, light scattering ${ }^{16}$, gel filtration ${ }^{18,19,20,21}$, osmotic pressure ${ }^{7}$, ${ }^{22}$, sedimentation equilibrium $9,14,27,24,25,26$ and sedimentation velocity ${ }^{7}$. This work uses a spectrophotometric-kinetic method to determine the tetramer-dimer equilibrium constant of rabbit hemoglobin. The said method has been chosen because it is less costly. The constants will be compared to those obtained by the use of other methods. Different derivatives will be used: oxyhemoglobin, carbonmonooxyhemoglobin, azidomethemoglobin and aquomethemoglobin.

The reactivity of hemoglobin can be monitored through the reactivity of the sulphydryl group. For this purpose the CysF9(93) $\beta$ sulphydryl group is the only group that is reactive towards 5,5'-dithiobis-(2nitrobenzoic acid) (DTNB). DTNB is a sulphydryl reagent which is particularly sensitive towards the environment of the sulphydryl group in hemoglobin ${ }^{20}$. . The aim of this work is to try and account for the different sulfhydryl reactivities of the different derivatives of hemoglobin ${ }^{33}$.

\section{Materials and Methods}

All materials used in this work were purchased from British Drug House, BDH and were analytical grade chemicals. Phosphate buffers with $\mathrm{pH} 7.4$ and ionic strength $0.05,0.5$ and 2.0 were prepared. The $\mathrm{pH}$ values were verified using a radiometer PHM 85 precision $\mathrm{pH}$ meter with a GK $2401 \mathrm{C}$ electrode. White rabbits were purchased locally and their necks slit while directing the blood into a beaker containing anticoagulant (acid-citrate dextrose solution). Hemoglobin was prepared by a standard laboratory procedure ${ }^{28}$. It was dialysed by using a dialyzing membrane, in a dialyzing solution. The dialyzing solution consisted of $5 \mathrm{ml}$ of $0.4 \mathrm{M}$ disodium hydrogen orthosphosphate, $10 \mathrm{ml}$ of $0.4 \mathrm{M}$ sodium dihydrogen orthosphosphate, $0.29 \mathrm{~g}$ of $\mathrm{NaCl}$ and $5 \mathrm{dm}^{3}$ of distilled water. Small ions and organic phosphate were removed by passing the hemoglobin through a Dintzis ion-exchange column.

\section{Determination of Hemoglobin Concentration}

The concentration of the prepared hemoglobin was determined by measuring at $540 \mathrm{~nm}$, the absorbance of $0.1 \mathrm{ml}$ of hemoglobin mixed with $3 \mathrm{ml}$ of Drabkin's solution. The molar extinction coefficient per heme at $540 \mathrm{~nm}$ is $\left.10,900 \mathrm{M}^{-1} \mathrm{~cm}^{-1(29-31}\right)$. A $2 \times 2 \mathrm{~cm}$ cell was used. The concentration, C, of hemoglobin was calculated thus;

$$
C=\frac{A b s(540 \mathrm{~nm})}{10,9000} \times \frac{(3+0.1)}{0.1} \text { moles heme } 1^{-1}
$$

\section{Preparation of Carbonmoxyhemoglobin}

Carbon monoxide was prepared by the action of concentrated tetraoxosulphate (IV) acid on sodium methanoate. The evolved gas was passed through wash bottles containing distilled water and $\mathrm{NaOH}$ to remove acid vapour.

Conversion to carbonmonoxyhemoglobin was effected by bubbling the gas produced through the oxyhemoglobin for 10mins. A colour change from bright red to pink was observed. The concentration of the carbonmonoxyhemoglobin was determined by taking the absorbance at $537.5 \mathrm{~nm}$, using a heme absorption coefficient of $1400 \mathrm{M}^{-1} \mathrm{~cm}^{-1(32)}$.

\section{Preparation of Aquomethhemoglobin}

A $1 \mathrm{M}$ of potassium ferricyanide was prepared by dissolving $0.33 \mathrm{~g}$ of its crystals in $1 \mathrm{ml}$ of water. A two-fold excess of the solution was added to oxyhemoglobin, and excess ferricyanide was removed by passing it through a Dintzis column ${ }^{28,33}$. The concentration of methemoglobin was determined by measuring the absorbance at $540 \mathrm{~nm}$ of a mixture $0.1 \mathrm{ml}$ aquomethemoglobin, $3 \mathrm{ml}$ distilled water and some potassium cyanide crystals; the molar absorptivity per heme at $540 \mathrm{~nm}$ is $10900 \mathrm{M}^{-1} \mathrm{~cm}^{-1}$. Methemoglobin samples were used within three days of preparation ${ }^{29,28}$. 


\section{Preparation of Azidomethemoglobin}

A $1 \mathrm{M}$ sodium azide solution was prepared by using freshly recrytallised sodium azide which had been left to dry for some days in a dessicator. The observed equilibrium constant, $\mathrm{K}_{\mathrm{obs}}$, for azide binding to aquomethemoglobins and rabbit have been determined previously ${ }^{29}$ as a function of $\mathrm{pH}$ at an ionic strength of 0.05 and $20^{\circ} \mathrm{C}$. The amount of azide required to give $99 \%$ reaction was calculated by using the equation

$$
\left[N_{3^{-}}\right]=\frac{99}{K_{o b s}}+0.99 C
$$

where $\mathrm{C}$ is the total aquomethemoglobin concentration in $\mathrm{M}, \mathrm{K}_{\mathrm{obs}}$ is the observed equilibrium constant at a given $\mathrm{pH}$.

The kinetics of the reaction of hemoglobin with DTNB was monitored in a phosphate buffer of $\mathrm{pH} 7.4$, ionic strength 0.05 , and containing $\mathrm{Na}_{2}$ EDTA.

$2 \mu \mathrm{M}$ to $100 \mu \mathrm{M}$ (heme) of hemoglobin were used. The kinetics were monitored at $412 \mathrm{~nm}$ on Zeiss PMQ II uv/visible spectrophotometer and recorded on a Phillips PM 8261 precision Xt chart recorder. The hemoglobin solutions were equilibrated at $20^{\circ} \mathrm{C}$ in a Lauda TUK 30 Kryostat. Each reaction was carried out thusly: $10 \mathrm{ml}$ of hemoglobin in the buffer solution was pipetted into a $2 \times 2 \mathrm{~cm}$ cuvette, which was then placed in the thermo-stated cell compartment of the spectrophotometer.

DTNB was added to give a concentration of $100 \mu \mathrm{M}$ in the cuvette. Transmittance as a function of time was recorded. This procedure was carried out four times for each concentration.

A different set of conditions was used in observing the reaction due to the hemoglobin dimers. A hemoglobin concentration of $2 \mu \mathrm{M}$ (heme) was used and phosphate buffer ( $\mathrm{pH} 7.4$ ) of ionic strength 2.0 was used. This was carried out about eight times for each derivative of hemoglobin.

\section{Results and Discussion}

The kinetics of the reaction of hemoglobin with DTNB is second order ${ }^{30}$. The apparent second order rate constants, $\mathrm{k}$, were calculated from the second order rate equation,

$\mathrm{k}=1 /(\mathrm{a}-\mathrm{b}) \mathrm{t} \ln (\mathrm{b}(\mathrm{a}-\mathrm{x}) / \mathrm{a}(\mathrm{b}-\mathrm{x}))$

Note: Equation 3 is valid if " $a$ " is not equal to " $b$ "

By inputting the values of transmittance as a function of time into a computer programme written for this purpose. In the above equation, $a$ is the initial concentration of DTNB in M; $b$ is the concentration of reacting sulphydryl groups in $\mathrm{M}$; and $x$ is the time dependent concentration of 2-thio-5-nitrobenzoate (TNB) in $\mathrm{M}$. This concentration was calculated from the molar absorptivity coefficient of TNB at different $\mathrm{pH}$ values ${ }^{31}, t$ is time in seconds.

The dissociation of hemoglobin tetramers to dimers may be depicted as

$$
\begin{array}{cc}
\mathrm{Hb}_{4} \leftarrow \rightarrow & 2 \mathrm{Hb}_{2} \\
(1-\alpha) & 2 \alpha
\end{array}
$$

where $\alpha$ is the fractional dissociation of tetramer into dimers. $\alpha$ is defined as

$$
\left(k-k_{t}\right) /\left(k_{d}-k_{t}\right)-------(4)
$$


where $\mathrm{k}$ is the apparent second order rate constant in a hemoglobin solution containing tetramer and dimer; $\mathrm{k}_{\mathrm{t}}$ is the limiting value of $\mathrm{k}$ at high hemoglobin concentration; and $\mathrm{k}_{\mathrm{d}}$ is the apparent second order rate constant for pure dimers.

The tetramer-dimer dissociation constant is defined as $\mathrm{K}_{4,2}=\left[\mathrm{Hb}_{2}\right]^{2} /\left[\mathrm{Hb}_{4}\right]$------- (5)

$$
\alpha=\alpha \mathrm{C}_{\mathrm{T}} /(1-\alpha) \text {------------------ }(6)
$$

where $\mathrm{C}_{\mathrm{T}}$ is the total concentration of hemoglobin in $\mathrm{M}$ (tetramer).

For oxyhemoglobin it was observed that as its concentration increased so did $\mathrm{k}$ decrease. This was so because of the fact that increasing concentration results in a decrease in the proportion of dimers in solution. Dimers are known to be more reactive than tetramers, hence, the decreasing reactivity at the higher concentration of hemoglobin.

For aquomethemoglobin, the variation of the afore-mentioned parameters showed that $\mathrm{k}$ increases as the concentration of methemoglobin decreases.

The variation of $\mathrm{k}$ with the concentration of carbonmonoxyhemoglobin showed that as the concentration of carbonmonoxyhemoglobin increased, the value of $\mathrm{k}$ decreased. For rabbit azidomethemoglobin, an obvious link between the concentration and the apparent second order rate constant, $\mathrm{k}$, was observed. As the former increased, the latter decreased, in keeping with the slower reactivity of the tetramers whose proportion increases at high concentration of hemoglobin.

The graphs in figures 2 to 5 show that the apparent second order rate constant reaction, decreases as the total concentration of hemoglobin increases. This is so because, it is known that Cys F9 [93] $\beta$ of hemoglobin dimers react faster than in tetramers ${ }^{13}$. Therefore, the trend of $\mathrm{k}$ seen in figures 2 to 5 arises because as the hemoglobin concentration increases, the proportion of dimers decreases. The fractional dissociation is seen to decrease for all the different derivatives of rabbit hemoglobin. It is thus seen that as $\mathrm{C}_{\mathrm{T}}$ increases, the value of $\alpha$ decreases. The value of $\mathrm{k}$ is also seen to decrease with increase in the value of $\mathrm{C}_{\mathrm{T}}$.

A plot of the apparent second-order rate constant versus $\mathrm{pH}$ shows a difference in reactivity for the different derivatives, namely azidomethemoglobin, carbonmonoxyhemglobin, oxyhemoglobin and aquomethemoglobin. This is shown in figure $1^{32}$. The aim of this work has been to try and account for the different sulfhydryl reactivities of the different derivatives of hemoglobin ${ }^{33}$. Reactivity increases in the order: azidomethemoglobin, oxyhemoglobin, carboxyhemoglobin and aquomethemoglobin. One therefore expects an increasing proportion of dimers in the afore-listed order, since hemoglobin dimers have a higher sulfhydryl reactivity than tetramers. The tetramer-dimer equilibrium constant has been determined for all the derivatives. This was based on the premise that the observed reactivity differences might be accounted for on the basis of differences in the degree of dissociation. This has been found not to be so, since the result obtained shows an equal degree of tetramer-dimer dissociation.

From Table 1, it is clear that the differences cannot be explained by a difference in the extent of dissociation. It is therefore not a plausible explanation for the observed difference in the apparent second order rate constant. 


\begin{tabular}{ll} 
Derivative & Tetramer-dimer constant $\mathbf{p K}_{\mathbf{4 , 2}}$ \\
\hline Oxyhemoglobin & $6.70 \pm 0.07$ \\
Carbonmonoxyhemoglobin & $7.16 \pm 0.06$ \\
Azidomethemoglobin & $7.10 \pm 0.07$ \\
Aquomethemoglobin & $7.02 \pm 0.08$ \\
\hline
\end{tabular}

It is interesting to note that the tetramer-dimer equilibrium constants determined were found to be in agreement with those determined by Chu, A.H. and Ackers, G.K. Journal of Biological Chemistry, 1981, 256, 1199. However, they carried out their determination by gel permeation chromatography and by the use of glycine buffer. One can say that the spectrophotometric-kinetic method employed for this work is valid.

\section{Acknowledgement}

This research was carried out with research grant awarded to Professor K.O. Okonjo by the Postgraduate school, University of Ibadan, Ibadan.

\section{References}

1. Lorenzen, K. (1997) Hemmstoffe der thrombocytenaggregation aus pilzen Biospekrum volume 1 page $1-27$

2. Solomon, B., Koppel., R., Hanan, E. and Katzav, T. (1996)

3. Rossi Fanelli, A, Antonini, E and Caputo, A (1964) Hemoglobin and Myoglobin. Advances in Protein Chemistry 19; $73-213$

4. Farmer M., Bonaventura C. and Benaventura J. (1982) Effects of anions and carbondioxide on the dissociation of liganded Human Hemoglobin and Human Hemoglobin variants. Hemoglobin and oxygen binding. Pages 257 - 262. Published by Elsevier North Holland

5. Reithel F.J. (1963). The dissociation and association of protein structures. Advances in Protein Chemistry 18: $124-215$

6. Prakash, V. (1992). Sedimentation Analysis of Seed Proteins. Analytical Ultracentrifugation in Biochemistry and Polymer Science chapter 24 pages 445 - 469

7. Kellet, G.L. (1971). Dissociation of Hemoglobin into subunits ligand-linked dissociation at neutral pH. Journal of Molecular Biology 59: 401 - 424

8. Otuno, G.I. MSc Thesis, University of Ibadan, Ibadan, 1998

9. Benhamon,N., Daune, M., Luzzati, A. and Weil, G. (1960). Etude de l'action du la concentration prote'ique sur la dissociation. Biochimica et Biophysica Acta, 37: 1 - 14

10. Cassasa, E.F. and Eisenberg, H (1964). Thermodynamic Analysis of Multi-component Solutions. Advances in Protein Chemistry volume 19: 287 - 387

11. Chiancone, E., Gilbert, L.M. , Gilbert, G.A. and Kellet, G.L.(1968). Dissociation of Hemoglobin Subunits: II Human oxyhemoglobin: Gel filtration studies. Journal of Biological Chemistry 243: $1212-1219$

12. Chu, A.H. and Ackers, G.K. (1981) Mutual Effects of Protons, $\mathrm{NaCl}$ and oygen on dimmer-tetramer assembly of human hemoglobin. Journal of Biological Chemistry256: 1199- 1205 
13. Manning, L.R., Jenkins, W.T., Hess, J.R. Vandegriff, K. , Winslow, R.M. and Manning, J.M., (1966). Subunit Dissociation in Natural and Recombinant Hemoglobins. Protein Science 5(4): 775 $-781$

14. Guidotti, G. (1967). Studies on the Chemistry of Hemoglobin I. The Reactive Sulphydryl Groups. Journal of Biological Chemistry 245: 3675 - 3684

15. Svedberg, T. (1937) Ultracentrifuge and the Study of High Molecular Compounds. Nature 139: $1051-1062$

16. Howlett, G.J. (1992) The Preparative Ultracentrifuge as an Analytical Tool. Analytical Ultracentrifugation in Biochemistry and Polymer Science, pages $32-48$. The Royal Society of Chemistry, Cambridge

17. Schachman, H.K. (1992) Is there a future for the ultracentrifuge? Analytical Ultracentrifugation in Biochemistry and Polymer Science, chapter 1, pages 3 - 15. The Royal Society of Chemistry, Cambridge

18. Kellet, G.L. and Schachman, H.K. (1971). Dissociation of Hemoglobin into subunits. Monomer formation and the influence of ligands. Journal of Molecular Biology 59: 387 - 399

19. Hemoglobin Laboratory Procedures, Chemistry Department, University of Ibadan, Ibadan. Compiled by Beetlestone, J.G. (1972)

20. Salinas, C., Garcia-Borron, J.C., Solano, F. and Lozano, J.A. (1994). Dopachrome tautomerase decreases the binding of indolic melanogenis intermediates to proteins. Biochimica et Biophysica Acta 1204 (1): $53-60$

21. Kurihara, K. and K. Shibata (1960) Arch. Biochem. Biophys. 88, 298

22. Austine, J.H. and Drabkin, D.L. (1935 - 1936). Spectrophotometric Studies III Methemoglobin. The Journal of Biological Chemistry, 112: $67-88$

23. Drabkin D.L. and Austine J.H. (1935 - 1936) Spectrophotometric Studies II: Preparations from washed blood cells; nitric oxide hemoglobin and sulthemoglobin. The Journal of Biological Chemistry (Baltimore), 112: $51-65$

24. Wiedermann B.L. and Olson J.S. (1975). Acceleration of Tetramer Formation by the Binding of Inositol Hexaphosphate to Hemoglobin Dimers. The Journal of Biological Chemistry (Baltimore) 250: $5273-5275$

25. Zwiderweg E.R.P., Hammers L.F., Bruin S.H. and Hilberg C.W. (1981). Equilibrium Aspects of the Binding of Myoinositol Hexakisphosphate to Human Hemoglobin as studied by ${ }^{31} \mathrm{PNMR}$ and $\mathrm{pH}-$ stat techniques. European Journal of Biochemistry (New York) 118: 85 - 94

26. Dintzis H.M. (1952) PhD Thesis. Harvard University

27. Antonini E., Brunori M., Caputo A., Chiancone E., Rossi F. and Wyman J. (1964). Studies on the Structure of Hemoglobin III. Physiochemical Properties of Reconstituted Hemoglobins. Biochemica et Biophysca Acta (Amsterdam) 79: $284-292$

28. Anuslem A.C.I. , Beetlestone J.G. and Irvine D. (1966). Reactivity differences between Hemoglobins Part IV. The reaction of human hemoglobins A and $\mathrm{C}$ with azide ion and the concept of heme-linked groups. Journal of Chemical Society (A) (London) $357-363$

29. Okonjo, K.O. (1972) PhD Thesis. University of Ibadan, Ibadan

30. Edelstein, S.J., M.J. Rahmar, J.S. Olson and Q.H. Gibson. Journal of Biological Chemistry 245, 4372

31. Amiconi, G., E. Antonini, M. Brunori, E. Chiancone and P. Vecchini (1971) Journal of Biological Chemistry 246, March 10

32. Rossi Fanelli, A., E. Antonini, and A. Caputo (1964). Advanced Protein Chemistry 19, 73

33. Kurihara, K. and K. Shibata (1960) Arch. Biochem. Biophys. 88, 298 